\title{
O FAZER PEDAGÓGICO DOS PROFESSORES DOS ANOS INICIAIS: INVESTIGANDO SUAS DIFICULDADES
}

\author{
THE PEDAGOGICAL PRACTICE OF TEACHERS IN THE EARLY YEARS: INVESTIGATING \\ THEIR DIFFICULTIES
}

LA PRÁCTICA PEDAGÓGICA DE LOS DOCENTES EN LOS PRIMEROS AÑOS: INVESTIGANDO SUS DIFICULTADES

\section{Bruna Ambros Baccin (iD) 9 \\ Mestrado em Educação em Ciências: Química da Vida e Saúde (UFSM) \\ Discente do Programa de Pós- Graduação em Educação em Ciências: Química da Vida e Saúde (PPGECQVS/UFSM) brunabaccin@hotmail.com}

\section{Luiza Frigo Pinto (iD) 9}

Mestrado em Educação em Ciências: Química da Vida e Saúde (UFSM)

Discente do Programa de PósGraduação em Educação em Ciências: Química da Vida e Saúde (PPGECQVS/UNIPAMPA) luiza.frigo@yahoo.com.br

\section{Renato Xavier Coutinho

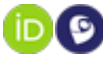

Doutorado em Educação em

Ciências: Química da Vida e Saúde (PPGECQVS/UFSM) Pró-reitor de Ensino do Instituto Federal Farroupilha (IFFar) Docente do Programa de PósGraduação em Educação em Ciências: Química da Vida e Saúde renato.coutinho@iffarroupilha.edu. $\underline{\text { br }}$

\begin{abstract}
Resumo
Este artigo apresenta os resultados de uma pesquisa realizada com professores dos anos iniciais de três escolas municipais de uma cidade do Rio Grande do Sul, Brasil. O objetivo deste estudo foi identificar as dificuldades enfrentadas pelos professores dos anos iniciais em sua prática docente. Tratou-se de uma pesquisa qualitativa exploratória, onde o público alvo foram dezesseis professores. Para a coleta dos dados, foram realizadas entrevistas e para a análise destas, foi utilizada a Análise Textual Discursiva. Os resultados do estudo permitem inferir que as principais dificuldades enfrentadas são relacionadas ao interesse do aluno, dificuldades na aprendizagem, problemas sociais e a ausência da família na escola. O estudo possibilitou observar ainda, a necessidade de formações continuadas dentro dos espaços escolares, a fim de capacitar os professores a trabalhar com as diferentes questões, permitindo dialogar sobre as dificuldades que surgem em sua prática.
\end{abstract}

Palavras-chave: Anos iniciais. Professores. Dificuldades. Prática docente

Recebido em: 29 de abril de 2021.

Aprovado em: 22 de junho de 2021.

Como citar esse artigo (ABNT):

BACCIN, Bruna Ambros; PINTO, Luiza Frigo; COUTINHO, Renato Xavier. O fazer pedagógico dos professores dos anos iniciais: investigando suas dificuldades. Revista Prática

Docente, v. 6, n. 2, e044, 2021.

http://doi.org/10.23926/RPD.2021.v6.n2.e044.id1149 


\section{Abstract}

This article presents the results of a survey carried out with teachers in the early years of three municipal schools in a city in Rio Grande do Sul, Brazil. The aim of this study was to identify the difficulties faced by teachers in the early years in their teaching practice. It was an exploratory qualitative research, where the target audience were sixteen teachers. For data collection, interviews were conducted and for their analysis, Discursive Textual Analysis was used. The results of the study allow us to infer that the main difficulties faced are related to the student's interest, learning difficulties, social problems and the absence of the family at school. The study also made it possible to observe the need for continued training within school spaces, in order to enable teachers to work with different issues, allowing for a dialogue about the difficulties that arise in their practice.

Keywords: Early years. Teachers. Difficulties. Teaching practice.

\section{Resumen}

Este artículo presenta los resultados de una investigación realizada con profesores de los años iniciales de tres escuelas municipales de una ciudad de Rio Grande do Sul, Brasil. El objetivo de este estudio fue identificar las dificultades que enfrentan los docentes en los primeros años en su práctica docente. Se desarrolló una investigación cualitativa exploratoria, donde el público participante fue dieciséis profesores. Para la recolección de datos se realizaron entrevistas y para su análisis se utilizó el Análisis Textual Discursivo. Los resultados del estudio permiten inferir que las principales dificultades enfrentadas están relacionadas con el interés del alumno, las dificultades de aprendizaje, los problemas sociales y la ausencia de la familia en la escuela. El estudio también permitió observar la necesidad de una formación continua dentro de los espacios escolares, a fin de capacitar a los docentes para trabajar con diferentes temas, permitiendo un diálogo sobre las dificultades que se presentan en su práctica.

Palabras clave: Primeros años. Maestros. Dificultades. Práctica docente. 


\section{INTRODUÇÃOO}

Os anos iniciais do ensino fundamental configuram-se como espaço privilegiado para o ensino de conteúdos conceituais, procedimentais e atitudinais (POZO; CRESPO, 2009). Sendo também possível, estimular o desenvolvimento da curiosidade, do senso de investigação e da criticidade, possibilitando a construção dos primeiros significados sobre o mundo, e a possibilidade de atuar ativamente no mundo em que vive, a partir de escolhas conscientes (VIECHENESKI; CARLETTO, 2013).

Para atuar neste contexto, admite-se a formação de professores realizada nas universidades e institutos superiores de educação, geralmente em cursos de Licenciatura em Pedagogia. Contudo, exige-se como formação mínima, segundo a Lei de Diretrizes e Bases da Educação Nacional (LDB), Lei n 9.394/96 (BRASIL, 1996), a modalidade Normal, oferecida em escolas de Ensino Médio.

Conforme as Diretrizes Curriculares Nacionais do curso de Pedagogia, instituída pela Resolução do Conselho Nacional de Educação, nº 01 de 15 de maio de 2006 (BRASIL, 2006), o pedagogo pode atuar em diversos níveis e modalidades de ensino, sendo responsável por ensinar Língua Portuguesa, Matemática, Ciências, História, Geografia, entre outras disciplinas, assumindo assim, um caráter polivalente.

Para Caixeta (2017) o professor polivalente é um sujeito capaz de apropriar-se e articular os conhecimentos básicos das diferentes áreas, que atualmente, compõem a base comum do currículo nacional dos anos iniciais do ensino fundamental. Entretanto, em pesquisa realizada por Gatti e Nunes (2009) constataram ser necessário ampliar a reflexão sobre a perspectiva polivalente, pois foi observado superficialidade em relação aos conteúdos específicos e maior aprofundamento nas questões pedagógicas.

Neste mesmo sentido, Longhini (2008) discute que é preciso repensar as estruturas curriculares dos cursos de Pedagogia, de modo a favorecer uma formação mais completa sobre os conteúdos específicos que devem ser ensinados nos anos iniciais, possibilitando a diminuição de dificuldades encontradas pelos professores em relação à abordagem de conteúdos mais específicos.

Por outro lado, os autores Lima (2012), Ivenicki (2019) e Vieira (2019) apontam em suas pesquisas outras dificuldades que os professores dessa etapa escolar vivenciam, relacionadas ao cotidiano escolar, as quais interferem de maneira significativa na dinâmica da escola, e que na maioria das vezes não dependem somente da iniciativa do professor em 
solucioná-las, pois são questões de ordem familiar, pessoal e social. E de acordo com Marcelo (2009, p.8):

[...]ser professor no século XXI pressupõe assumir que o conhecimento e os alunos [...] se transformam a uma velocidade maior à que estávamos habituados e que, para se continuar a dar uma resposta adequada ao direito de aprender dos alunos, teremos de fazer um esforço redobrado para continuar a aprender.

Dessa maneira, os professores precisam estar em constante aprendizado, na perspectiva de estimular a curiosidade, o interesse e a participação dos alunos em sala de aula, pois vivemos em uma sociedade que está em constante transformação, e nesse contexto a escola se modifica também.

Nesse sentido, aponta-se para a necessidade da realização de formações continuadas nos espaços escolares, envolvendo a discussão de temas pertinentes às áreas de estudo, problematizando assuntos de cunho teórico/prático, compartilhando experiências, buscando nortear, enriquecer e consolidar o fazer pedagógico.

Para tanto, entende-se que os processos de formação continuada a serem realizados nas escolas, precisam considerar os saberes dos professores, os quais são oriundos de sua formação inicial, do seu cotidiano, suas experiências e relações com as outras pessoas, pois é a partir destes que o professor dialoga com os outros saberes, tendo em mente que estes não se desvinculam do professor, pois foram adquiridos ao longo do tempo, e, portanto, fazem parte de sua identidade profissional (TARDIF, 2014).

Assim, a partir destas considerações, apresenta-se este estudo, que possui como objetivo identificar as dificuldades enfrentadas pelos professores dos anos iniciais do ensino fundamental em sua prática docente. Por conseguinte, a investigação ocorreu a partir de entrevistas semiestruturadas, realizadas com professores dos anos iniciais do ensino fundamental de três escolas municipais do Rio Grande do Sul.

\section{Procedimentos Metodológicos}

Este estudo constitui-se de uma pesquisa qualitativa, de cunho exploratório, que de acordo com Gil (2010) é desenvolvida com o objetivo de proporcionar uma visão geral, do tipo aproximativo, acerca de determinado fato, onde muitas vezes, as pesquisas exploratórias constituem a primeira etapa de uma investigação mais ampla.

A coleta de dados ocorreu através de entrevistas semiestruturadas, as quais foram gravadas em áudio e posteriormente transcritas para a análise. Participaram da pesquisa dezesseis professores, os quais foram identificados a partir de letras e números, e as escolas 
também receberam etiquetas de identificação, sendo: professores da escola A (P01 ao P10), da escola B (P11 ao P15) e da escola C (P15 ao P16).

Destaca-se ainda, que as escolas investigadas apresentam contextos diferentes, onde a escola A localiza-se nas proximidades do centro da cidade, atende alunos de classe média, exibindo infraestrutura adequada as necessidades dos alunos. Por outro lado, a escola B localizada na periferia da cidade, revela uma realidade de dificuldades econômicas e assistenciais.

A escola $\mathrm{C}$, localiza-se na zona rural do município, aproximadamente $30 \mathrm{~km}$ da cidade, evidencia dificuldades de acesso à escola pelo fato de alunos e professores necessitarem de transporte escolar, comunicação, pois apresenta precariedade do sinal de telefonia e internet. Esta escola possui uma turma multisseriada, ou seja, uma professora atende duas turmas de níveis de ensino, dividindo a mesma sala de aula.

O roteiro das entrevistas apresentou três (03) questões abertas sobre as dificuldades enfrentadas no cotidiano do professor, este está disposto no quadro abaixo (Quadro 1):

Quadro 1 - Roteiro das entrevistas

1- Quais as suas maiores dificuldades em sala de aula?

2- Quais os motivos que você apontaria para essas dificuldades?

3- Conseguiu resolver essas dificuldades?

Fonte: Dados da Pesquisa.

Para a análise dos materiais coletados utilizou-se a Análise Textual Discursiva (ATD) (MORAES; GALIAZZI, 2016), a qual é uma metodologia de análise de dados e informações de natureza qualitativa, com a finalidade de produzir novas compreensões sobre os fenômenos e discursos, onde as entrevistas realizadas configuram-se como o corpus da pesquisa. A ATD se estrutura a partir de três etapas:

1) Desmontagem dos textos ou unitarização: nesta etapa, implica em examinar os textos em seus detalhes, fragmentando-os em Unidades de Sentido, as quais receberam a letra $\mathrm{E}_{-}$ (escola $\mathrm{A}, \mathrm{B}$ ou $\mathrm{C})$, o número de professores foi identificado pela letra $\mathrm{P}_{-}(01$ ao 16$)$ e o número da questão identificado pela letra Q_ (01 ao 04).

2) Estabelecimento de relações ou categorização: consiste na construção de relações entre as Unidades de Sentido, este processo resulta no agrupamento de elementos semelhantes, as categorias. Nesta etapa do processo obteve-se um total de dezessete (16) categorias iniciais, com cento e cinco (105) unidades de sentido. 
Em seguida, após leitura aprofundada das categorias iniciais, bem como de suas Unidades de Sentido, chegou-se às categorias intermediárias, estabelecendo um total de três (03) categorias, sendo intituladas: Prática docente; Anseios do ser professor; e Enfrentamentos da escola, conforme apresentado no Quadro 2:

Quadro 2 - Categorias emergentes da análise

\begin{tabular}{|c|c|c|c|}
\hline Categorias iniciais & $\begin{array}{c}\text { Número de unidades } \\
\text { de sentido }\end{array}$ & Categorias intermediárias & $\begin{array}{c}\text { Número de unidades de } \\
\text { sentido }\end{array}$ \\
\hline Formação inicial & 1 & \multirow{5}{*}{ PRÁTICA DOCENTE } & \multirow{5}{*}{38} \\
\hline $\begin{array}{c}\text { Problemas da prática } \\
\text { docente }\end{array}$ & 19 & & \\
\hline Multisseriação & 3 & & \\
\hline Teoria e prática & 1 & & \\
\hline $\begin{array}{c}\text { Metodologias de sala } \\
\text { de aula }\end{array}$ & 14 & & \\
\hline Professor reflexivo & 11 & \multirow{5}{*}{$\begin{array}{l}\text { ANSEIOS DO SER } \\
\text { PROFESSOR }\end{array}$} & \multirow{5}{*}{40} \\
\hline Interesse & 5 & & \\
\hline $\begin{array}{l}\text { Dificuldades na } \\
\text { aprendizagem }\end{array}$ & 9 & & \\
\hline Aprendizagem efetiva & 4 & & \\
\hline Estrutura familiar & 11 & & \\
\hline A família na escola & 8 & \multirow{5}{*}{ Enfrentamentos da escola } & \multirow{5}{*}{27} \\
\hline Inclusão & 6 & & \\
\hline Sexualidade na escola & 6 & & \\
\hline Violência e Drogas & 1 & & \\
\hline $\begin{array}{l}\text { Estrutura da escola: } \\
\text { física e pessoal }\end{array}$ & 6 & & \\
\hline Total: 16 & 105 & 03 & 105 \\
\hline
\end{tabular}

Fonte: Dados da Pesquisa.

Durante a análise das categorias intermediárias, vislumbrou-se a possibilidade de agrupá-las em uma única categoria final, sendo: "A escola como espaço de compartilhamento de dificuldades, saberes e anseios: um olhar para a práxis docente". Que de acordo com Moraes e Galiazzi (2016) é um movimento que age no sentido de superar a fragmentação, em direção a descrições e compreensões mais holísticas e globalizadas.

3) Comunicação ou produção de metatextos: nessa etapa, percebe-se uma nova compreensão do todo, possibilitada pelo intenso envolvimento nas etapas anteriores. O objetivo agora será elaborar um texto descritivo e interpretativo, o qual denomina-se metatexto, a partir das categorias encontradas.

\section{Resultados E discussões}


Partindo para a análise dos resultados obtidos, apresenta-se o perfil profissional dos professores investigados, onde do total de dezesseis (16) professores dos anos iniciais, apenas um (01) professor é do gênero masculino e o período de docência destes, varia de um ano (01) a trinta e sete (37) anos de docência.

Em relação à predominância do gênero feminino entre os professores dos anos iniciais, a autora Louro (2006) coloca que "Se o destino primordial da mulher era a maternidade, bastaria pensar que o magistério representava de certa forma, uma extensão da maternidade", "cada aluno ou aluna, vistos como filho ou filha espiritual [...]" (LOURO, 2006, p. 450), sendo uma tarefa que as mulheres já executavam em seus lares, por isso, estavam preparadas para cuidar das crianças na escola (GONÇALVES; FARIA; REIS, 2016).

Quanto à formação acadêmica destes profissionais identificou-se: onze (11) professores formados em Pedagogia e cinco (05) formados em Magistério. Sendo que desse total de dezesseis (16) professores, um (01) tem outras três formações acadêmicas em nível superior, e três (03) professores apresentam, além da formação no Magistério ou em Pedagogia, outra formação acadêmica. Ainda pode-se constatar que quatro (04) professores possuem pósgraduação na área da educação.

Desse modo, ao iniciar a construção dos metatextos através da transformação das categorias em textos, o pesquisador passa a realizar suas interpretações pessoais, considerando as informações obtidas com os sujeitos da pesquisa, mantendo fidelidade e respeito às mesmas (MORAES; GALIAZZI, 2016). Apresentam-se as categorias intermediárias através das quais busca-se explorar, justificar e teorizar sobre a categoria final deste estudo, conforme os subtópicos abaixo:

\subsection{Prática docente}

Intitulou-se esta categoria como Prática Docente apoiando-se em Arruda (2014), onde conforme a autora, constitui como o trabalho pedagógico, o qual pode ser considerado um conjunto de pressupostos teóricos, concepções (a respeito da educação, e do ensino), práticas e ações educativas planejadas e realizadas pelos docentes com a finalidade de favorecer a aprendizagem e o desenvolvimento dos estudantes.

Ainda, para Pozo (2002, p. 69), na prática docente observa-se que “quem aprende é o aluno; o que o professor pode fazer é facilitar mais ou menos sua aprendizagem. Como? Criando determinadas condições favoráveis para que se ponham em marcha os processos de aprendizagem adequados". 
Nesta categoria, foram reunidas cinco (05) categorias iniciais, agrupando um total de trinta e oito (38) Unidades de Sentido, conforme apresentado no quadro (2). Partindo para a análise das respostas obtidas através das entrevistas, observam-se apontamentos com relação à formação inicial dos professores, como pode ser observado na resposta:

A gente tem a formação na faculdade ali, é bem mínima né! (Professor EAP03-2)

Nesse sentido, de acordo com Testoni et al. (2016) a formação superior oferecida ao futuro professor dos anos iniciais, no Brasil, parece focalizar mais os processos pedagógicos, esquecendo-se da abordagem dos conhecimentos específicos necessários, o que parece causar uma lacuna no desenvolvimento profissional do docente.

Segundo os autores Gatti; Nunes (2009), Lima (2007) e Caixeta (2017) a formação dos professores dos anos iniciais possibilita a formação de um professor polivalente, que conforme o Referencial Curricular Nacional para a Educação Infantil (RCNEI) precisa "ser polivalente significa que ao professor cabe trabalhar com conteúdos de naturezas diversas que abrangem desde cuidados básicos essenciais até conhecimentos específicos provenientes das diversas áreas do conhecimento" (BRASIL, 1998, p. 41).

Em pesquisa, Silveira e Fabri (2020, p.170) constataram que:

nos cursos de graduação a área de Ciências é tratada de maneira aligeirada e, por sua vez, no exercício de sua atividade profissional esses professores recebem e/ou procuram formações voltadas para as áreas de Português e Matemática continuando o Ensino de Ciências em segundo plano.

Portanto, compreende-se que é necessário ampliar a reflexão sobre a adequação das perspectivas polivalentes e interdisciplinares, pois se observa que a formação inicial ofertada aos professores dos anos iniciais apresenta superficialidade no trato dos conteúdos das diferentes áreas do conhecimento (CRUZ; RAMOS; SILVA, 2017).

Destacam-se ainda, outras dificuldades mencionadas durante as entrevistas:

Só em questão mais do tempo, que as vezes tu planejas uma coisa, tempo de planejamento, e tu não dá conta, em função do tempo que passar muito rápido. (Professor EAP06-1)

Assim, ao referir-se ao planejamento observa-se que, conforme Leal (2005, p. 2) este “[...] deve estar presente em todo o processo educativo por ser uma previsão sobre o que irá acontecer, é um processo de reflexão sobre a prática docente, sobre seus objetivos, sobre o que está acontecendo, sobre o que aconteceu". Ao planejar, uma coisa é certa, nem sempre as ações e atividades preparadas previstas no planejamento serão realizadas na sequência ou no momento esperado, pois, fatores adversos podem interferir e não há como prever, no entanto, é preciso 
ter em mente que este é flexível, podendo ser reestruturado conforme eventual necessidade (SANTOS, 2013).

Ainda, pode-se destacar no contexto investigado, a multisseriação, um desafio a ser enfrentado por um dos professores da escola $\mathrm{C}$, como pode ser analisado por meio da resposta abaixo:

A multisseriação, porque eu penso que é um regresso, eu penso que é um regresso porque turmas multiseriadas tu trabalhas um pouco com uma, um pouco com a outra e tu tens que dar atenção pra uns, tem que dar atenção para outros e todos eles exigem a tua atenção, principalmente no primeiro que é a alfabetização. (Professor ECP16-1)

A multisseriação configura-se como uma prática que reúne no mesmo espaço duas turmas de níveis de ensino diferentes, no entanto de acordo com a resposta é possível perceber que esta é uma organização que dificulta o trabalho do professor, pois requer muita atenção e um complexo planejamento das atividades.

Quando um sistema de ensino opta pela multisseriação, em muitos casos, isto não vem associada a um conjunto de orientações pedagógicas, que poderia ser oferecida ao professor, facilitando o trabalho nestas turmas. De acordo com Parente (2014 p.59) "Essa ausência de orientação leva, muitas vezes, a reproduções do modelo seriado na própria multissérie, o que acarreta trabalhos duplicados ou, até mesmo, quintuplicados, tendo em vista a junção de alunos matriculados em diferentes séries/anos.”

Corroborando com isso, Hage (2014) e Antunes; Ribas (2015) colocam que a organização da lógica seriada dificulta o trabalho dos professores, pois se sobrecarregam nos afazeres diários e principalmente não compreendem a turma como um coletivo, partindo da proposta que dividir os sujeitos e seu planejamento é a melhor maneira de ensinar, assim é necessária uma formação adequada para atuar nesse contexto.

Outra dificuldade apontada pelos professores é a dificuldade de relacionar a teoria e a prática em sala de aula, como pode ser observado com base na resposta abaixo:

É a gente sempre vai nos cursos, mas assim é um pouco decepcionante, porque aí vai num curso, tu vê métodos legais, ah poderia aplicar esse e esse mas a gente vem pra realidade e não vai, isso que é frustrante, porque é muito bonito, tipo agora essa semana, tivemos um palestra sobre inclusão, aí tu chega lá tem que fazer isso, aí tu chega na escola e vai tentar fazer não é assim, isso é uma das coisas que sempre me angustiou, na teoria é tudo muito bonito né, lá na faculdade, mas quando tu vem aqui na prática não adianta. (Professor EAP02-4)

A partir dessa resposta, entende-se que a teoria e prática precisam dialogar permanentemente no processo pedagógico para que o ensino e aprendizagem aconteçam de forma efetiva (FORTUNA, 2015). Neste sentido, compreende-se que esta não é uma tarefa 
simples, por isso, sugere-se que os profissionais responsáveis pelos cursos de formação mantenham contato com os professores, estando disponíveis para auxiliá-los e orientá-los em suas dúvidas e dificuldades.

Ainda de acordo com Fortuna (2015) teoria e prática são inseparáveis, tornando-se através desta relação, práxis autêntica, que possibilita aos sujeitos reflexão sobre a ação, proporcionando uma educação para a liberdade. De acordo com Freire (1987, p.38) “A práxis, porém, é reflexão e ação dos homens sobre o mundo para transformá-lo. Sem ela, é impossível a superação da contradição opressor-oprimido [...]".

$\mathrm{Na}$ perspectiva de relacionar teoria e prática os professores entrevistados mencionam que buscam utilizar de situações cotidianas para ensinar diferentes conteúdos, utilizam ainda diferentes metodologias, conforme apontado nas respostas abaixo:

\footnotetext{
Uma gincana, um trabalho em grupo, uma brincadeira, tu consegue achar o ponto certo pra ti chegar ao aluno, pra tentar ajudar ele da melhor forma, então é através de dinâmicas e conversas. (Professor EBP14-3)
}

A gente vai trabalhando com joguinhos, alguma coisa diferente, que chame a atenção deles. (Professor EAP08-3)

Nesse sentido, observa-se que os professores buscam alternativas que envolvam os alunos em atividades que proporcionam momentos de investigação, curiosidade e descoberta, na tentativa de tornar o processo de ensino-aprendizagem mais dinâmico e atrativo, colocando o aluno no centro desse processo (BORGES; ALENCAR, 2014). No entanto, é necessário planejamento ao utilizar diferentes metodologias, considerando os objetivos da atividade, conteúdos envolvidos e tempo estimado, para que não seja apenas um momento de diversão, mas uma prática que possa contribuir para a aprendizagem.

\subsection{ANSEIOS DO SER PROFESSOR}

Esta categoria reúne os anseios e preocupações dos professores, as quais estão presentes em seu cotidiano, essas inquietações o fazem refletir constantemente sobre suas práticas e seu contexto. Ao refletir sobre sua prática, entende-se que o professor está sempre em busca de novos conhecimentos e maneiras de ensinar, de forma a despertar o interesse dos alunos e melhorar a qualidade do ensino (LEONE, 2011).

Desse modo, esta categoria reuniu cinco (5) categorias iniciais, agrupando um total de quarenta (40) Unidades de Sentido que apresentaram situações destacadas anteriormente. A questão do professor que reflete sobre sua prática, pode ser comprovada através das respostas: 
A gente que é professor ensina e aprende ao mesmo tempo, é a troca. (Professor EAP10-4)

E a gente tem que correr atrás e estudar para poder trabalhar com eles. (Professor EAP03-2)

De acordo com Schön (1992, p.4), “[...] um professor reflexivo tem a tarefa de encorajar e reconhecer, e mesmo de dar valor à confusão dos seus alunos. Mas também faz parte das suas incumbências encorajar e dar valor à sua própria confusão [...]”. Para ele, um professor reflexivo se forma com base em três ideias centrais: a reflexão na ação, a reflexão sobre a ação e a reflexão sobre a reflexão na ação.

Assim sendo, a prática reflexiva é o meio pelo qual o professor torna-se também um pesquisador, investigador de sua própria prática, buscando se aperfeiçoar através de leituras e observações. Entretanto, outros pontos preocupam o professor, como a falta de interesse e a dificuldade na aprendizagem dos alunos, conforme apontado nas respostas abaixo:

Olha eu que acho que as maiores dificuldades é quando a gente tem alunos com dificuldade de aprendizagem. (Professor EAP06-1)

É a falta de interesse é o que mais assim preocupante, não tem como colocar interesse na criança, é por mais que ela tenha dificuldade, se ela tem interesse tu consegue avançar, tu consegue progredir com ela, mas se ela não tem interesse, ela não tem motivação. (Professor EAP06-1)

Ressalta-se que a falta de interesse e a dificuldade na aprendizagem, destacadas pelos professores podem estar atreladas a diferentes fatores, em consonância com o estudo realizado por Silva (2012), o qual aponta que a forma de ensinar, a insegurança familiar, falta de atenção ou até mesmo problemas como déficit de atenção, falta de material escolar, a fome, conflitos com colegas, desentendimento com professores e também a repetência do ano letivo, podem ocasionar as dificuldades apontadas acima.

Por outro viés, estudos de Silva e Schneider (2007) e Bertti (2018), relatam que a afetividade e a motivação são fatores que implicam diretamente no desenvolvimento emocional e afetivo, na socialização, nas interações humanas e, sobretudo, na aprendizagem.

Nesse sentido para Wachowicz (2009, p. 18) "na educação escolar, nem sempre os alunos querem aprender. A obrigatoriedade da matrícula coloca-os nas salas de aula, eles tornam-se amigos de alguns de seus colegas e passam a querer ir à escola”. Desse modo é importante que se crie na escola, um ambiente alegre, interativo, dinâmico, o qual possa despertar além da amizade entre os indivíduos, a vontade de ali estar, permanecer e aprender juntos. 
Diante desse contexto, os professores precisam buscar constantemente inovar em suas aulas de forma a atrair a atenção e interesse dos alunos, envolvendo-os em atividades nas quais eles possam interagir e participar, conforme relato abaixo:

É muito importante porque a criança aprende fazendo, $70 \%$ da aprendizagem da criança é aquilo que ele faz, pratica, porque só ouvindo, escrevendo ele pode esquecer sabe, mas aquilo que ele faz, ele não vai esquecer mais. (Professor EAP09-4)

Assim, entende-se que o envolvimento do aluno em atividades escolares tem se mostrado essencial para o desempenho escolar, influenciando em fatores como o interesse na aprendizagem, desempenho, atenuando até mesmo o abandono escolar (GONÇALVES, 2017).

Outra questão que preocupa os professores investigados é a falta de estrutura familiar observada nas escolas, a qual também pode ser uma das causas do desinteresse dos alunos, conforme apontado na resposta abaixo:

\section{A família é tudo porque se a criança tem dificuldade, e os pais mostrando oh, vamos ver o que tu fez, eles vão querer fazer melhor para mostrar em casa, caprichar, copiar, porque as vezes têm criança que não quer copiar, não quer fazer, pode isso? (Professor EAP06-2)}

Dessa forma, compreende-se que é necessário o apoio familiar para que o aluno se sinta motivado para participar das aulas. Ainda segundo com os professores, observa-se a ausência dos pais em reuniões, a falta de alimentação, materiais escolares e roupas, o que de acordo com Sawaya (2006) podem comprometer de alguma maneira a capacidade de atenção e a disposição para aprender.

\subsection{ENFRENTAMENTOS DA ESCOLA}

Esta categoria reúne questões que são vivenciadas pela escola e que demandam ações conjuntas com as famílias e a sociedade, pois a construção de uma escola inclusiva, crítica, reflexiva e de qualidade é um enorme desafio, tendo em vista que requer muito além da formação profissional dos professores, visto que que envolvem questões familiares, sociais e de infraestrutura da escola (LIMA, 2012).

Assim, nesta categoria foram reunidas cinco (05) categorias iniciais, totalizando vinte e sete (27) Unidades de Sentido. Dessa forma, um dos grandes enfrentamentos das escolas hoje é a questão do apoio e participação da família na vida escolar do aluno, conforme mencionado nas respostas abaixo:

Voltamos a questão do apoio familiar, que tem muitos alunos que a gente não tem, eu tenho casos de alunos ali que inclusive são cinco anos dele na escola, e eu não conheço a família, porque não vieram até a escola. (Professor EBP14-1) 
Família, lidar com a família, os pais não aceitam não participam, ou não frequentam né, os alunos são quase isolados, tem ali mãe que eu nem conheço, que tu chamas e não vem, porque sabe dos problemas. (Professor EBP12-1)

Ainda, durante as entrevistas os professores mencionaram que desconhecem alguns pais, pois estes não costumam participar das reuniões na escola, e de acordo com Tonche (2014) a influência familiar é decisiva na aprendizagem dos alunos. Segundo a autora, os filhos de pais extremamente ausentes vivenciam sentimentos de desvalorização e carência afetiva, gerando desconfiança, insegurança, improdutividade e desinteresse, sérios obstáculos à aprendizagem escolar.

De acordo com López (2009, p. 27) “O contato entre a família e a escola é necessário em qualquer idade, durante os primeiros anos ele terá de ser bem mais intenso para coordenar as atividades educativas", facilitando o diálogo entre professores e alunos, participando de reuniões, incentivando a leitura e auxiliando nos deveres de casa.

A relação entre escola e família, contribui em diversos aspectos, conforme mencionado acima, podendo ainda auxiliar no processo de integração/inclusão de alunos com deficiência, pois, com a orientação da família, os professores podem adquirir maior proximidade do aluno, entendendo seus hábitos e preferências, possibilitando assim, a construção de uma relação de confiança, como apresentado nas respostas a seguir:

Como atender os alunos inclusos, atender e entender cada aluno. (Professor EAP021)

Com necessidades especiais, porque fica mais complicado, embora tu consigas trabalhar. (Professor EAP06-1)

Conforme estabelecido na Lei Brasileira de Inclusão da Pessoa com Deficiência (Lei n ${ }^{\circ}$ 13.146/2015) "requer o compromisso com os alunos com deficiência, reconhecendo a necessidade de práticas pedagógicas inclusivas e de diferenciação curricular" (BRASIL, 2015). Contudo, ainda são perceptíveis as dificuldades encontradas pelos professores quanto ao atendimento de alunos inclusos, pois não se sentem seguros em sua prática.

Nesse sentido, Cunha (2011, p.100) afirma que:

Não podemos pensar em inclusão escolar, sem pensarmos em ambiente inclusivo. Inclusivo não somente em razão dos recursos pedagógicos, mas também pelas qualidades humanas. Apesar de um espaço atraente e adequado para a instrução escolar ser uma necessidade elementar na educação, não raramente, deparamos com escolas sem o devido preparo nesse requisito.

Partindo desse pressuposto, são necessárias ações que viabilizem não apenas a construção de um ambiente inclusivo, mas que preparem os sujeitos envolvidos nesse processo para colaborar na promoção de um atendimento educacional de qualidade, buscando a inclusão 
desses alunos. Desse modo, os professores precisam estar preparados para ensinar com muita criatividade, desenvolvendo atividades que favoreçam a aprendizagem dos alunos (CARVALHO et al., 2017).

No entanto, além das dificuldades já apontadas, os professores dos anos iniciais relatam ainda a preocupação com as questões de cunho social, as quais são situações que o professor sozinho não consegue resolver, pois, demandam a participação da família, sociedade e também de políticas públicas de qualidade, conforme pode ser observado nas respostas abaixo:

Tem a questão da prostituição no nosso município, da droga, a questão de certos alertas, sobre o que tem que fazer ou não, nessa questão eu tenho alertar eles, eu prefiro parar a aula, sentar, quando um tem dúvida eu paro a aula, converso com eles, que que eu poderia fazer, o que eu não posso fazer. (Professor EAPO4-5)

Já eu tenho uma de 14 anos e tenho três de 13, essas já me deram problemas de namoro com guri da quarta série, então aí o conflito gerou e deu um conflito bem sério. Daí a pequena me perguntou porque eles se escondiam? Iam fazer o que? Aí tu ficas como? (Professor EAP04-2)

Ainda, foram relatados outros problemas sociais, como a falta de acesso à internet, saúde, transporte, drogas, violência, exploração sexual de menores, desemprego e a pobreza. Nesse sentido, para Catão (2011, p.461) “o problema social pode ser compreendido pela análise da relação entre a situação atual e a situação desejada", assim os problemas sociais são produtos de um sistema social, econômico, político e cultural.

Nesse contexto, a escola passa a assumir um papel social, em um mundo em constante transformação, se equilibrando entre a função de preparar cidadãos e a de desenvolver suas qualidades para a vida em sociedade. Ao mesmo tempo, deve exercitar a sua função crítica, estudando e analisando os problemas que interferem em sua realidade, procurando transformálos (GOMES, 2014).

Destaca-se que, as escolas municipais investigadas contam com a parceria da Rede de Apoio Integrada (RAI), a qual possui profissionais de diferentes áreas, como psicopedagogos, psicólogos, fonoaudióloga, educadora especial e os órgãos municipais (Conselho Tutelar, Centro de Referência de Assistência Social - CRAS). Essa parceria auxilia os professores em suas dúvidas, anseios e possibilita a assistência adequada e gratuita aos alunos com dificuldades.

No entanto, destaca-se ainda que embora exista essa rede de apoio, os professores relatam que nem sempre é fácil conseguir com que todos os alunos que precisam sejam atendidos, pois, a demanda de atendimentos dos profissionais ligados a RAI é alta. Tais 
considerações são feitas com base nas respostas obtidas durante as entrevistas, como os exemplos:

É a falta de profissionais para nos ajudar, falta reforço, falta de psicólogo que tu precisarias. (Professor EAP06-1)

Eu até conversei com as gurias porque assim, nós temos a psicopedagoga né aqui, que daí ela atende, que eu acho que ela seria mais pra essas dificuldades aí, mas o problema agora é que ela está sem horário. (Professor EAP10-3)

Assim, os profissionais da rede de apoio em conjunto com os professores formam uma equipe multiprofissional, representando mediadores importantes no processo de inclusão social, contribuindo para um diálogo entre família, aluno e a escola.

Outro aspecto mencionado pelos professores é relacionado com a infraestrutura da escola, como a falta de acesso à internet, falta de monitores, ausência de professores e manutenção dos espaços escolares. De acordo com Satyro e Soares (2007) essas questões afetam diretamente a qualidade da educação e influenciam diretamente no desempenho dos alunos.

Portanto, após as reflexões realizadas neste estudo e da discussão das categorias intermediárias obtidas através da ATD, que originaram a categoria final do estudo "A escola como espaço de compartilhamento de dificuldades, saberes e anseios: um olhar para a práxis docente" é possível observar que os professores investigados, apesar de atuarem em realidades diferentes, compartilham das mesmas dificuldades e possuem relatos semelhantes, possibilitando assim a construção dessa categoria mais ampla.

Tais apontamentos giram em torno das dificuldades familiares, marcadas pela ausência da família na escola, falta de um suporte emocional que auxilie, acompanhe e motive o aluno. Observa-se ainda, dificuldades sociais, identificadas pelo pouco acesso à internet, aos livros, à alimentação de qualidade, material escolar e até mesmo com relação às políticas de assistência à saúde dos alunos.

Nesse sentido, entende-se que batalhar por uma educação de qualidade não é uma tarefa somente dos professores, mas toda a sociedade precisa cobrar políticas públicas voltadas para a escola. Não basta apontarmos onde estão as dificuldades, é preciso buscar através de ações que estas sejam corrigidas e que possamos juntos alavancar a qualidade da educação, bem como da sociedade em que vivemos, pois, uma reflete a outra.

Pois, conforme o Estatuto da Criança e do Adolescente (ECA):

É dever da família, da comunidade, da sociedade em geral e do Poder Público assegurar com absoluta prioridade, a efetivação dos direitos referentes à vida, à saúde, 
à alimentação, à educação, ao esporte, ao lazer, à profissionalização, à cultura, à dignidade, à liberdade e a convivência familiar e comunitária (BRASIL, 1990).

E mesmo a legislação sendo tão clara e forneça todo o embasamento legal no que tange a tais apontamentos, isso não tem sido suficiente para superar esses enfrentamentos indicados pelos professores entrevistados, mas como já mencionado, é necessário batalhar por melhorias na educação, condições de trabalho e buscando também, o cumprimento das leis, pois esta é uma tarefa de toda a sociedade.

\section{CONSIDERAÇÕES FinAIS}

Partindo do objetivo proposto neste trabalho de identificar as dificuldades enfrentadas pelos professores dos anos iniciais do ensino fundamental em sua prática docente, pode-se constatar que de modo geral, estas são variadas, perpassam pelo interesse do aluno, dificuldades na aprendizagem, inclusão, problemas sociais, presença da família na escola e a multisseriação.

Nesse sentido, entende-se que algumas dessas dificuldades são complexas para serem superadas, visto que não dependem somente da vontade do professor em modificá-las, mas sim, de todo um suporte além da escola. Compreende-se que algumas dessas questões são preocupações inerentes a prática docente, como o interesse do aluno pelos conteúdos/aulas e as dificuldades no processo ensino-aprendizagem.

A categoria final encontrada durante a análise, "A escola como espaço de compartilhamento de dificuldades, saberes e anseios: um olhar para a práxis docente", revela um panorama das escolas investigadas, as quais possuem características diferentes com relação aos locais em que estão inseridas e ao público que atendem, mas que compartilham das mesmas preocupações com relação à aprendizagem dos alunos e a qualidade da educação fornecidas nas escolas.

Os dados encontrados sugerem a necessidade de formações continuadas nos espaços escolares, a fim de capacitar os professores a trabalhar com as questões identificadas neste estudo. Observa-se também, a necessidade de um acompanhamento junto aos professores, para que se sentirem amparados na realização das atividades, permitindo assim, dialogar sobre seus anseios e dificuldades.

Por fim, cabe ainda ressaltar que este estudo não teve por finalidade responsabilizar os professores pelos dados encontrados, mas sim, fazer um levantamento de modo a se aprofundar nessa realidade, buscando assim, uma aproximação com esse campo de estudo na intenção de futuras colaborações com a escola, através de atividades a serem desenvolvidas. 


\section{REFERÊNCIAS}

ANTUNES, Helenise Sangoi; RIBAS, Juliana da Rosa. O caderno de educação do campo: possibilidades de reflexão sobre o Pacto Nacional pela alfabetização na idade certa. Políticas educativas, v.8, n.2, p. 104-118, 2015. Disponível em:

https://seer.ufrgs.br/Poled/article/view/56224/34807. Acesso em: 16 out. 2020.

ARRUDA, Tatiana Santos. A Criatividade no Trabalho Pedagógico do Professor e o Movimento em sua Subjetividade. 2014. 271 f. Brasília: Tese (Doutorado em Educação) Universidade de Brasília, Brasília, 2014. Disponível em:

https://repositorio.unb.br/handle/10482/17574. Acesso em:15 de out. 2020.

BERTTI, Carolina Teixeira. A influência dos aspectos emocionais nos distúrbios de aprendizagem. REnCiMa, v. 9, n.5, p. 01-13, 2018. Disponível em:

https://doi.org/10.26843/rencima.v9i5. Acesso em: 25 out. 2020.

BORGES, Tiago Silva; ALENCAR, Gidélia. Metodologias ativas na promoção da formação crítica do estudante: o uso das metodologias ativas como recurso didático na formação crítica do estudante do ensino superior. Cairu em Revista, n.4, v.3, p. 119-143, 2014. Disponível em: https://www.cairu.br/revista/artigos4.html. Acesso em: 29 set. 2020.

BRASIL. Lei no 8.069 de 13 de julho de 1990. Estatuto da Criança e do Adolescente - ECA. Diário Oficial da União, Brasília, DF, 1990. Disponível em:

http://www.planalto.gov.br/ccivil_03/leis/18069.htm. Acesso em: 27 set. 2020.

BRASIL. Lei no 9.394 de 20 de dezembro de 1996. Lei de Diretrizes e Bases da Educação Nacional. Diário Oficial da União, Brasília, DF, 1996. Disponível em:

http://www.planalto.gov.br/ccivil_03/leis/19394.htm. Acesso em: 19 set. 2020.

BRASIL. Referencial curricular nacional para a educação infantil. Ministério da Educação e do Desporto. Secretaria de Educação Fundamental. Brasília: MEC/SEF, 1998. Disponível em: http://portal.mec.gov.br/seb/arquivos/pdf/rcnei_vol1.pdf. Acesso em: 28 out. 2020.

BRASIL. Diretrizes Curriculares Nacionais para o Curso de Graduação em Pedagogia. Conselho Nacional da Educação. Diário Oficial da União, Brasília, DF, 2006. Disponível em: https://www.ufrgs.br/pedagogia/legislacao/diretrizes-curriculares-nacionais. Acesso em: 17 nov. 2020.

BRASIL. Lei no 13.146 de 6 de julho de 2015. Lei Brasileira de Inclusão da Pessoa com Deficiência. Diário Oficial da União, Brasília, DF, 2015. Disponível em:

http://www.planalto.gov.br/ccivil_03/_ato2015-2018/2015/lei/113146.htm. Acesso em: 26 nov. 2020.

CAIXETA, Sara da Silva. Unidocência: uma análise do trabalho pedagógico de professoras dos anos iniciais do ensino fundamental. 2017.134 f. Minas Gerais: Dissertação (Mestrado em Educação) - Universidade Federal de Uberlândia, Minas Gerais, 2017. Disponível em: https://repositorio.ufu.br/handle/123456789/20691. Acesso em: 05 nov. 2020.

CARVALHO, Maria Aparecida Alves Sobreira et al. A formação de professores para 
educação inclusiva. In: XIII CONGRESSO NACIONAL DE EDUCAÇÃO, 13, 2017, Curitiba. Anais... Curitiba: Editora Universitária Champagnat, 2017, p. 10501-10518. Disponível em: https://educere.bruc.com.br/arquivo/pdf2017/22981_11845.pdf. Acesso em: 05 nov. 2020.

CATÃO, Maria de Fátima. O ser humano e problemas sociais: questões de intervenção. Temas em Psicologia, v. 19, n. 2, p. 459-465. 2011. Disponível em: http://pepsic.bvsalud.org/pdf/tp/v19n2/v19n2a09.pdf. Acesso em: 19 out. 2020.

CRUZ, Shirleide Pereira da Silva; RAMOS, Nathália Barros; SILVA, Kátia Augusta Curado Pinheiro Cordeiro da. Concepções de polivalência e professor polivalente: uma análise histórico-legal. Revista HISTEDBR On-line, v.17, n.4, p.1186-1204, 2017. DOI 10.20396/rho.v17i2.8645863. Acesso em: 05 nov. 2020.

CUNHA, Eugênio. Autismo inclusão: psicopedagogia práticas educativas na escola e na família. 7 ed. Rio de Janeiro: Wak, 2011.

FORTUNA, Volnei. A relação teoria e prática na educação em Freire. Revista Brasileira de Ensino Superior, n. 1, v. 2, p. 64-72, 2015. Disponível em: https://seer.imed.edu.br/index.php/REBES/article/view/1056/746. Acesso em: 16 out. 2020.

FREIRE, Paulo. Pedagogia do Oprimido. 17 ed. Rio de Janeiro: Paz e Terra, 1987.

GATTI, Bernadete Angelina; NUNES, Marina Muniz Rossa. Formação de professores para o ensino fundamental: estudo de currículos das licenciaturas em pedagogia, língua portuguesa, matemática e ciências biológicas. São Paulo: Fundação Carlos Chagas, 2009. em: http://www.fcc.org.br/pesquisa/publicacoes/textos_fcc/arquivos/1463/arquivoAnexado.pdf. Acesso em: 10 de fev.2020.

GIL, Antônio Carlos. Métodos e técnicas de pesquisa social. 6 ed. São Paulo: Atlas, 2010.

GOMES, Alessandra de Oliveira Capuchinho. A função social da escola: uma análise das significações constituídas pelos gestores, professores, pais e alunos de uma escola pública paulista. 2014. 525f. São Paulo: Tese (Doutorado em Educação: Psicologia da Educação) Pontifícia Universidade Católica de São Paulo, São Paulo, 2014. Disponível em: https://tede2.pucsp.br/handle/handle/16164. Acesso em: 25 de out.2020.

GONÇALVES, Josiane Peres; FARIA, Adriana Horta de.; REIS, Maria das Graças Fernandes de Amorim dos. Olhares de professores homens de Educação Infantil: conquistas e preconceitos. Perspectiva, v. 34, n. 3, p. 988-1014, 2016. Disponível em: https://periodicos.ufsc.br/index.php/perspectiva/article/view/2175795X.2016v34n3p988/pdf_1. Acesso em: 07 set. 2020.

GONÇALVES, Sara Sofia Basílio. Envolvimento do aluno na escola, perceção de apoio familiar e desempenho escolar. 2017. 103 f. Portugal: Dissertação (Mestrado em Psicologia da Educação) - Universidade da Madeira, Portugal, 2017. Disponível em: http://hdl.handle.net/10400.13/1909. Acesso em: 25 de out.2020.

HAGE, Salomão Antônio Mufarrej. Transgressão do Paradigma da (Multi) seriação como referência para a construção da escola pública do campo. Educação \& Sociedade, v. 35, n. 
129, p. 1165-1182, 2014. Disponível em: https://www.scielo.br/pdf/es/v35n129/0101-7330es-35-129-01165.pdf. Acesso em: 19 out. 2020.

IVENICKI, Ana. A Escola e seus Desafios na Contemporaneidade. Ensaio: Avaliação e Políticas Públicas em Educação, v.27, n.102, p. 1-8, 2019. http://dx.doi.org/10.1590/s0104$\underline{40362018002700001}$

LEAL, Regina Barros. Planejamento de Ensino: peculiaridades significativas. Revista Iberoamericana de Educación, v. 27, n.03, p. 1-6, 2005.

https://doi.org/10.35362/rie3732705. Acesso em: 03 out. 2020.

LEONE, Naiara Mendonça. Necessidades formativas dos professores dos anos iniciais na sua inserção no exercício da docência. 2011. 320 f. São Paulo: Dissertação (Mestrado em Educação) - Universidade Estadual Paulista, Presidente Prudente, São Paulo, 2011.

Disponível em: https://repositorio.unesp.br/handle/11449/90200. Acesso em: 29 out. 2020.

LIMA, Vanda Moreira Machado. Formação do professor polivalente e os saberes docentes: um estudo a partir de escolas públicas. 2007. 282f. São Paulo: Tese (Doutorado em Educação) - Universidade de São Paulo, São Paulo, 2007. Disponível em: https://www.teses.usp.br/teses/disponiveis/48/48134/tde-12032009-111920/en.php. Acesso em: 05 nov. 2020.

LIMA, Vanda Moreira Machado. A complexidade da docência nos anos iniciais na escola pública. Nuances: estudos sobre educação, v. 22, n. 23, p. 148-166, 2012.

http://dx.doi.org/10.14572/nuances.v22i23.1767

LONGHINI, Marcos Daniel. O conhecimento do conteúdo científico e a formação do professor das séries iniciais do Ensino Fundamental. Investigações em Ensino de Ciências, 13(2), p. 241-253, 2008. Disponível em:

https://www.if.ufrgs.br/cref/ojs/index.php/ienci/article/view/441. Acesso em: 01 out. 2020.

LÓPEZ, Jaume Sarramona. Educação na família e na escola: o que é, como se faz. 2 Ed. São Paulo: Editora Loyola, 2009.

LOURO, Guacira Lopes. Mulheres na sala de aula. In: PRIORE, Mary Del (Org.). História das mulheres no Brasil. 8 ed. São Paulo: Contexto, 2006.

MARCELO, Carlos. Desenvolvimento profissional docente: passado e futuro. Ciências da Educação, n.8, 2009, p.7-22. Disponível em:

http://www.unitau.br/files/arquivos/category_1/MARCELO_Desenvolvimento_Profissional Docente_passado_e futuro_1386180263.pdf. Acesso em: 25 out. 2020.

MORAES, Roque; GALIAZZI, Maria do Carmo. Análise Textual Discursiva. 3 ed. Ijuí: Unijuí, 2016.

PARENTE, Cláudia da Mota Darós. Escolas Multisseriadas: a experiência internacional e reflexões para o caso brasileiro. Ensaio: Avaliação e Políticas públicas em Educação, v.22, n. 82, p. 57-88, 2014. Disponível em: https://doi.org/10.1590/S0104-40362014000100004. Acesso em: 14 jun. 2021. 
POZO, Juan Ignácio.; CRESPO, Miguel Angel Gomes. A aprendizagem e o ensino de ciências: do conhecimento cotidiano ao conhecimento científico. 5. ed. Porto Alegre: Artmed, 2009.

POZO, Juan Ignacio. Aprendizes e mestres: a nova cultura da aprendizagem. Trad.: Ernani Rosa. Porto Alegre: Artmed, 2002.

SANTOS, Andréia dos. Planejamento de ensino: suas contribuições no processo de ensino e aprendizagem na escola municipal Papa Pio XII. 2013. 43f. Curitiba: Monografia (Especialização em Educação: Métodos e técnicas de Ensino) - Universidade Tecnológica Federal do Paraná, Curitiba, 2013. Disponível em:

http://repositorio.utfpr.edu.br/jspui/handle/1/20901. Acesso em: 05 de out. 2020.

SATYRO, Natália; SOARES, Sergei. A infraestrutura das escolas brasileiras de ensino fundamental: um estudo com base nos censos escolares de 1997 a 2005. Brasília: IPEA, 2007. Disponível em: https://ipea.gov.br/portal/images/stories/PDFs/TDs/td_1267.pdf. Acesso em: 28 out. 2020.

SAWAYA, Sandra Maria. Desnutrição e baixo rendimento escolar: contribuições críticas. Estudos Avançados, v.20, n. 58, p. 133-146, 2006. Disponível: https://www.scielo.br/pdf/ea/v20n58/13.pdf?fbclid=IwAR1xrD62xDRpYiEpnPTkitEtixtxtC7 Usy7dUKLSD1esbm8 768gOMidow8. Acesso em: 28 mar. 2020.

SCHÖN, Donald. Formar professores como profissionais reflexivos. In: NÓVOA, Antônio (coord.). Os professores e a sua formação. Lisboa: Publicações Dom Quixote, 1992.

SILVA, Daniela Neves da. A Desmotivação do Professor em Sala de Aula, nas Escolas Públicas do Município de São José dos Campos - SP. 2012. 52f. Curitiba: Monografia (Especialização em Gestão Pública Municipal), Universidade Tecnológica Federal do Paraná, Curitiba, 2012. https://doi.org/10.17765/1516-2664.2020v25n1p210-226

SILVA, Jamile Beatriz Carneiro; SCHNEIDER, Ernani José. Aspectos socioafetivos do processo de ensino e aprendizagem. Revista de divulgação técnico-científica do ICPG, v.3, n.11, p. 83-87, 2007. Disponível em: https://silo.tips/download/aspectos-socioafetivos-doprocesso-de-ensino-e-aprendizagem. Acesso em: 03 out. 2020.

SILVEIRA, Rosemari Monteiro Castilho Foggiatto; FABRI, Fabiane. Formação continuada para professores dos anos iniciais: enfoque ciência, tecnologia, sociedade (cts) no ensino de ciências. REnCiMa, v. 11, n.4, p. 169-190, 2020. Disponível em: https://doi.org/10.26843/rencima.v11i4. Acesso em:10 out. 2020.

TARDIF, Maurice. Saberes docentes e formação profissional. 17. ed. Petrópolis, Rio de Janeiro: Vozes, 2014.

TESTONI, Leonardo et al. Ensino de Ciências nas séries iniciais: repensando a formação docente no Brasil. Revista Tecné, Episteme y Didaxis: TED, n. extraordinário, p. 76-85, 2016. Disponível em: https://revistas.pedagogica.edu.co/index.php/TED/article/view/4423. Acesso em: 14 out. 2020.

TONCHE, Josiane Cipriano da Silva. O desinteresse dos alunos das séries iniciais do 
ensino fundamental pela educação escolar: causas e possíveis intervenções. 2014. 20 f. Curitiba: Monografia (Especialização em Coordenação Pedagógica), Universidade Federal do Paraná, Curitiba, 2014. Disponível em: https://hdl.handle.net/1884/47110. Acesso em: 07 de out. 2020

VIECHENESKI, Juliana Pinto; CARLETTO, Márcia. Por que e para quê ensinar ciências para crianças. Revista Brasileira de Ensino de Ciências e Tecnologia, v. 6, n. 2, 2013. DOI: 10.3895/S1982-873X2013000200014.

VIEIRA, Alexia Júlia Lima. Os desafios da profissão docente vivenciados por professores/as com diferentes tempos de carreira. 2019. $78 \mathrm{f}$. Paraíba: Trabalho de Conclusão de Curso (Monografia Licenciatura em Pedagogia) - Universidade Federal da Paraíba, João Pessoa, 2019. Disponível em:

https://repositorio.ufpb.br/jspui/bitstream/123456789/15249/1/AJLV29052019.pdf. Acesso em: 17 dez. 2020.

WACHOWICZ, Lilian Anna. Pedagogia mediadora. 1 ed. Petrópolis: Vozes, 2009.

\section{AgRadecimentos}

À Coordenação de Aperfeiçoamento de Pessoal de Nível Superior (CAPES) e ao Conselho Nacional de Desenvolvimento Científico e Tecnológico (CNPq) pelo apoio financeiro à pesquisa. 